\title{
3-Nitrooxypropanol Decreased Enteric Methane Production From Growing Beef Cattle in a Commercial Feedlot: Implications for Sustainable Beef Cattle Production
}

OPEN ACCESS

Edited by:

Metha Wanapat

Khon Kaen University, Thailand

Reviewed by:

Jon Schoonmaker

Purdue University, United States

Vinícius Carneiro De Souza,

Virginia Tech, United States

*Correspondence:

Karen A. Beauchemin

karen.beauchemin@canada.ca

${ }^{\dagger}$ Present address:

Aklilu W. Alemu,

Swift Current Research and Development Center, Agriculture and Agri-Food Canada, Swift Current, SK,

Canada

Specialty section:

This article was submitted to Animal Nutrition,

a section of the journal

Frontiers in Animal Science

Received: 14 December 2020

Accepted: 26 January 2021

Published: 16 February 2021

Citation:

Alemu AW, Pekrul LKD, Shreck AL,

Booker CW, McGinn SM,

Kindermann $M$ and Beauchemin KA (2021) 3-Nitrooxypropanol Decreased

Enteric Methane Production From Growing Beef Cattle in a Commercial

Feedlot: Implications for Sustainable Beef Cattle Production.

Front. Anim. Sci. 2:641590.

doi: 10.3389/fanim.2021.641590

\section{Aklilu W. Alemu ${ }^{1 \dagger}$, Liana K. D. Pekrul' ${ }^{2}$, Adam L. Shreck ${ }^{2}$, Calvin W. Booker ${ }^{2}$, Sean M. McGinn ${ }^{1}$, Maik Kindermann ${ }^{3}$ and Karen A. Beauchemin ${ }^{1 *}$}

${ }^{1}$ Lethbridge Research and Development Center, Agriculture and Agri-Food Canada, Lethbridge, AB, Canada, ${ }^{2}$ Feedlot Health Management Services, Okotoks, AB, Canada, ${ }^{3}$ DSM Nutritional Products, Animal Nutrition and Health, Kaiseraugst, Switzerland

Effects of the investigational methane $\left(\mathrm{CH}_{4}\right)$ inhibitor 3-nitrooxypropanol (3-NOP) on animal performance, health and enteric $\mathrm{CH}_{4}$ production of beef cattle were evaluated in a commercial feedlot. Two concurrent studies were conducted: a large pen study $(4,048$ cattle, eight pen replicates per experimental group) to measure animal performance and health and a small pen study (a subset of 50 cattle from the large pen study, $n=25$ per experimental group) to measure enteric $\mathrm{CH}_{4}$ emissions. Within the study, animals (body weight $\pm \mathrm{SD}, 282 \pm 8 \mathrm{~kg}$ ) were assigned in a completely randomized design to one of two groups: control, fed a backgrounding diet (70\% corn or barley silage, 30\% steam-flaked barley grain concentrate; dry matter (DM) basis) and 3-NOP, fed the backgrounding diet containing 3-NOP. The treatment group in the large pen study was adapted to 3-NOP (12 $\pm 3 \mathrm{~d}$ ) before receiving the final target level of $200 \mathrm{mg} / \mathrm{kg}$ of DM, which was fed for 108 $\pm 8 \mathrm{~d}$. Animals in the small pen $\mathrm{CH}_{4}$ emissions study received a basal diet or a basal diet with 3-NOP, with the dose increased every $28 \mathrm{~d}$ : low (150 mg/kg DM; $1.27 \mathrm{~g} / \mathrm{d}$ ), medium (175 mg/kg DM; $2.25 \mathrm{~g} / \mathrm{d})$, and high (200 mg/kg DM; $2.75 \mathrm{~g} / \mathrm{d})$. Intake in the small pens was monitored by electronic feeding bunks and $\mathrm{CH}_{4}$ was measured using the GreenFeed system. In the large pen study, total weight gained, average daily gain, and animal health variables were not affected by 3-NOP, but DM intake (DMI) tended to decrease $(P=0.06)$ by $2.6 \%$ relative to control $(8.07 \mathrm{~kg} / \mathrm{d})$, while gain:feed ratio tended to be improved $(P=0.06)$ by $2.5 \%$ relative to control $(0.161 \mathrm{~kg}$ weight gain $/ \mathrm{kg} \mathrm{DMI})$. In the small pen study, average daily consumption of 3-NOP increased with inclusion rate whereas average DMl was decreased by $5.4 \%(P=0.02)$ compared with control $(10.4 \mathrm{~kg} / \mathrm{d})$. On average, addition of 3-NOP decreased $(P=0.001) \mathrm{CH}_{4}$ emissions $(\mathrm{g} / \mathrm{d})$ by $25.7 \%$ and yield ( $\mathrm{g} \mathrm{CH}_{4} / \mathrm{kg}$ DMI) by $21.7 \%$. In conclusion, supplementing a backgrounding diet with 3-NOP decreased $\mathrm{CH}_{4}$ yield and tended to improve feed efficiency of beef cattle fed in a commercial feedlot with no negative impacts on animal health.

Keywords: beef cattle, enteric methane, environmental sustainability, greenhouse gas emissions, methane inhibitor 


\section{INTRODUCTION}

As countries move toward greenhouse gas (GHG) emission neutrality by 2050 there is increasing pressure on ruminant livestock production to reduce enteric methane $\left(\mathrm{CH}_{4}\right)$ emissions. The Special Report of the International Panel on Climate Change [Intergovernmental Panel on Climate Change (IPCC), 2018] calls for a 24-27\% reduction in $\mathrm{CH}_{4}$ emissions from agriculture in order to limit a potential temperature increase to $1.5^{\circ} \mathrm{C}$. Methane has a much shorter lifetime (half-life; 8.6 years) than carbon dioxide $\left(\mathrm{CO}_{2}\right)$ in the atmosphere ( $>100$ years, Muller and Muller, 2017), which makes it attractive for short-term gains in global warming abatement. Enteric $\mathrm{CH}_{4}$ from ruminants comprises $\sim 4-6 \%$ of global anthropogenic GHG emissions ( $40 \%$ of all livestock emissions; Gerber et al., 2013). As a result, there is an urgent need to develop technologies and mitigation strategies that can be cost-effectively adopted by cattle producers to lessen the contribution of ruminant livestock to GHG emissions (Beauchemin et al., 2020).

Ruminant livestock produce enteric $\mathrm{CH}_{4}$ as an end product of feed digestion. In the rumen, polysaccharides (mainly cellulose, hemicellulose, and starch) are hydrolyzed to glucose and other hexoses and pentoses, with the monosaccharides further metabolized to volatile fatty acids, $\mathrm{CO}_{2}$ and dihydrogen $\left(\mathrm{H}_{2}\right)$. The volatile fatty acids are used by the animal as a main source of energy, while $\mathrm{CO}_{2}$ and $\mathrm{H}_{2}$ are used to form $\mathrm{CH}_{4}$, which is eructated to the atmosphere via the breath. This process allows ruminants to derive nutrients from forages and other cellulosic materials, thereby avoiding direct competition with humans. However, $\mathrm{CH}_{4}$ is a potent $\mathrm{GHG}$ with a global warming potential of 28-times that of $\mathrm{CO}_{2}$ [over a 100-year period, Intergovernmental Panel on Climate Change (IPCC), 2013].

A broad range of potential mitigation strategies has been proposed to decrease $\mathrm{CH}_{4}$ emissions as outlined by comprehensive reviews (Hristov et al., 2013; Beauchemin et al., 2020). Among the strategies proposed, the investigational $\mathrm{CH}_{4}$ inhibitor 3-nitrooxypropanol (3-NOP; DSM Nutritional Products Ltd., Kaiseraugst, Switzerland) shows tremendous promise with $20-80 \%$ decreases in $\mathrm{CH}_{4}$ production depending upon the type of animal, diet composition, dose and method of supplementation (Hristov et al., 2015; Vyas et al., 2016a, 2018; Dijkstra et al., 2018; McGinn et al., 2019). This inhibitor reduces methanogenesis in the rumen by inactivating the enzyme methyl-coenzyme $M$ reductase used by archaea (Duin et al., 2016). The decrease in $\mathrm{CH}_{4}$ production was shown to persist over several months when 3-NOP was included in the diets of lactating dairy cows (25-32\% decrease, 12-week study; Hristov et al., 2015) and growing beef cattle (37-42\% decrease over 238 d; Vyas et al., 2018).

Incorporating 3-NOP into beef cattle diets to decrease $\mathrm{CH}_{4}$ production could allow producers to participate in the carbon market, such as the carbon pricing system in Canada (Government of Canada, 2019), by trading $\mathrm{CO}_{2}$ equivalents. Additionally, any improvement in animal performance [body weight (BW) gain, feed conversion efficiency] resulting from feeding 3-NOP could help offset the additional costs of using the feed additive. Therefore, it is important to evaluate, at a commercial scale, the results for $\mathrm{CH}_{4}$ mitigation and animal performance reported in controlled research studies that evaluated 3-NOP. Previous beef cattle studies were conducted using individually housed animals (Romero-Perez et al., 2014, 2015) or small pens ( $\leq 10$ cattle/pen) of animals (Vyas et al., 2016a,b, 2018) that minimize social interactions among animals and thus do not reflect the conditions of commercial feedlots where animals are housed in large groups (>100 cattle/pen). Thus, the objectives of this study were to evaluate the effects of feeding 3-NOP to backgrounded beef cattle on feed consumption, animal performance, animal health and enteric $\mathrm{CH}_{4}$ production in a commercial feedlot setting.

\section{MATERIALS AND METHODS \\ Research Overview, Site Description, and Diet}

Two concurrent studies were conducted using procedures in accordance with the guidelines of the Canadian Council on Animal Care (2009) and with approval of the Veterinary Drug Directorate of Health Canada (DSTS No. 207171). The animal performance study evaluated the effects of 3-NOP supplementation on dry matter intake (DMI), average daily gain (ADG), feed conversion efficiency (gain:feed ratio, G:F), and health using cattle housed in 16 commercial feedlot pens. The effects of 3-NOP on enteric $\mathrm{CH}_{4}$ production were evaluated in a second study using a subset of cattle maintained in two small pens. The animal performance study was conducted between November 2017 and September 2018 for a total of $108 \pm 8 \mathrm{~d}$ (12 $\pm 3 \mathrm{~d}$ of adaptation, $89 \pm 8 \mathrm{~d}$ at the final concentration for measurements), while the $\mathrm{CH}_{4}$ production study was conducted between May and September, 2018 for a total of $112 \mathrm{~d}$ (28 d of adaptation, $84 \mathrm{~d}$ of measurement).

The research was conducted at a commercial beef cattle feedlot located near Nanton, Alberta, Canada. The basic design of the feedlot is representative of standard designs used in western Canada where animals are housed in open-air, dirtfloor pens arranged side-by-side with central feed alleys and $20 \%$ porosity wood-fence windbreaks. The 16 large pens used in the performance study had dimensions of $\sim 61 \mathrm{~m} \times 70 \mathrm{~m}$ with a capacity of $\sim 250$ animals per pen and were equipped with a concrete feed bunk along one side of the pen. The two small pens used in the $\mathrm{CH}_{4}$ production study had dimensions of $\sim 15.5 \mathrm{~m} \times 29.9 \mathrm{~m}$ with a capacity of 25 animals per pen and were equipped with four electronic feed bunks (GrowSafe, Calgary, Alberta, Canada) per pen. One of the pens was equipped with a GreenFeed emission monitoring (GEM) system (CLock Inc., Rapid City, SD, USA). There were three animal handling facilities located at the site. Each facility contained a hydraulic chute equipped with an individual animal scale, a chute-side computer with individual animal data collection and management software $\left(i\right.$ FHMS $^{\complement}$; Feedlot Health Management Systems, Okotoks, Alberta, Canada), and separation alleys to facilitate the return of animals to designated pens. Open-air containment pens are located adjacent to each facility. 
A total of 4,048 mixed breed steers were assigned to the two concurrent studies. In the large pen study, the cattle were fed a backgrounding diet containing $70 \%$ whole crop barley (Hordeum vulgare L.) silage and 30\% barley-based concentrate [dry matter (DM) basis; Table 1]. In the small pen study, the initial diet formulation contained barley silage but due to an unexpected shortage, corn silage (Zea mays) was used midway (starting August 19, 2018) until the end of the experiment. Micro-ingredients (ionophore, antibiotic, minerals, vitamins, and 3-NOP) were added to the ration via a water-based microingredient machine. The ionophore monensin (Rumensin, Elanco Canada Limited, Guelph, Ontario, Canada) was included at $25 \mathrm{mg} / \mathrm{kg} \mathrm{DM}$ and chlortetracycline (Chlor 100, Bio-Agri Mix, Mitchell, Ontario, Canada) was included at $35 \mathrm{mg} / \mathrm{kg} \mathrm{DM}$ for liver abscess control. The 3-NOP was a dry granular product with an active ingredient concentration of $100 \mathrm{~g} 3-\mathrm{NOP} / \mathrm{kg}$. The rations were mixed thoroughly before delivery into the feed bunks, and prior to starting the experiment, the mixer underwent testing to validate the weigh scale and mixing consistency.

\section{Animal Performance and Health Study}

The animal performance and health study was conducted in large pens (average 253 animals/pen; range: 244-263 animals/pen), with eight replicates. Each replicate was assigned to two pens; control and 3-NOP, and thus the experimental unit was the pen ( $n=8 /$ treatment group). Animals (mixed breed beef steer calves) for the study were sourced from various auction markets across Canada and randomly allocated to treatments upon arrival to the feedlot or at re-handling (39 d after arrival). The average $( \pm S D)$ initial individual animal live weight of study pens was $283 \pm 9$ and $282 \pm 8 \mathrm{~kg}$ for the control and 3-NOP groups, respectively. Animals in the control group (2,025 animals) were fed the

TABLE 1 | Ingredient inclusion rate and diet composition (mean \pm SD) for the basal diet used in the animal performance and methane production studies.

\begin{tabular}{lc}
\hline Item & Basal diet $^{\text {a }}$ \\
\hline Diet ingredients, \% of DM & \\
Barley silage or corn silage & 70.14 \\
Steam-flaked barley grain & 28.74 \\
Supplement & 1.12 \\
Diet composition, \% of DM & \\
DM, \% as-fed & $39.4 \pm 2.26$ \\
Organic matter & $92.2 \pm 0.40$ \\
NDF & $44.0 \pm 3.24$ \\
ADF & $22.0 \pm 1.59$ \\
CP & $12.0 \pm 1.96$ \\
Gross energy, MJ/kg DM & $21.4 \pm 0.67$ \\
\hline
\end{tabular}

${ }^{a}$ Combined analysis of control diet and diets containing 3-NOP.

${ }^{b}$ Barley silage contained (DM basis): $53.2 \pm 1.47 \%$ NDF, $28.4 \pm 2.21 \%$ ADF, $13.7 \pm$ $1.15 \% \mathrm{CP}$, and $21.8 \pm 0.56 \mathrm{MJ} / \mathrm{kg}$ gross energy; corn silage contained (DM basis): 51.7 $\pm 1.02 \% \mathrm{NDF}, 28.4 \pm 0.80 \% \mathrm{ADF}, 8.6 \pm 0.79 \% \mathrm{CP}$, and $21.8 \pm 0.17 \mathrm{MJ} / \mathrm{kg}$ gross energy; steam-flaked barley grain contained (DM basis): $20.5 \pm 2.99 \% \mathrm{NDF}, 5.5 \pm 0.60 \% \mathrm{ADF}$, $12.3 \pm 1.02 \% \mathrm{CP}$, and $20.9 \pm 0.58 \mathrm{MJ} / \mathrm{kg}$ gross energy.

cIncludes: Limestone, vitamin-trace mineral premix, monensin sodium (to provide 25 mg/kg; Rumensin, Elanco Canada Limited, Guelph, Ontario, Canada), chlortetracycline (to provide 35 mg/kg; Chlor 100, Bio-Agri Mix, Mitchell, Ontario, Canada). backgrounding basal diet without 3-NOP whereas animals in the 3 -NOP group (2,023 animals) were fed the same basal diet containing 3-NOP at a concentration of $200 \mathrm{mg} / \mathrm{kg} \mathrm{DM}$ basis. Animals in the 3-NOP group were incrementally adapted to reach the final concentration of 3-NOP: $100 \mathrm{mg} 3-\mathrm{NOP} / \mathrm{kg}$ DM for 7-10 d, $150 \mathrm{mg} 3-\mathrm{NOP} / \mathrm{kg} \mathrm{DM}$ for $7 \mathrm{~d}$, and the final concentration of $200 \mathrm{mg} / \mathrm{kg} \mathrm{DM}$ until the end of the study. The dose of 3-NOP was based on previous studies including Vyas et al. (2016a,b, 2018) and Romero-Perez et al. (2014, 2015).

Feed was delivered twice daily (and topped-up throughout the day when needed) by mixer trucks equipped with load cells. Feed bunks were monitored every day before morning feeding and feed adjustment was made based on slick-bunk management (Schwartzkopf-Genswein et al., 2003; Schutz et al., 2011). Daily DMI was calculated as the total feed delivered to the pen daily, adjusted for DM content, divided by the number of animals in the pen. As minimal feed remained in the feed bunk prior to the next day's feed allocation, it was not necessary to account for feed refusals.

Animal health was monitored by experienced herdsmen and veterinarians. The herdsmen conducted health monitoring on a daily basis and used subjective criteria based on modified DART system (Depression, Appetite, Respiratory signs and Temperature; Step et al., 2008) for identification and further evaluation and treatment of sick animals. Animals were weighed before feeding (non-fasted) once at the start and once at the end of the study to determine body weight (BW) gain. The weight gain was divided by number of days on the study to calculate ADG (shrunk), and feed conversion efficiency was measured as G:F (kg:kg) ratio by dividing ADG by daily DMI.

\section{Methane Production Study}

A subset of animals allocated to one of the replicates (Replicate 8) in the animal performance and health study ( 80 animals, 40 from each experimental group) were removed from the large pens at the start of the study, weighed over two consecutive days (nonfasted), and ranked by BW. Twenty-five candidate animals from each group were then selected based on BW to provide two balanced groups for the $\mathrm{CH}_{4}$ production study. The remaining 15 animals from each experimental group were returned to the appropriate large pen. The selected animals (initial BW $=328 \pm$ $29 \mathrm{~kg}$ ) were maintained on their respective experimental group assignments throughout the study: control and 3-NOP. Prior to starting the study, the animals in the 3-NOP group received the backgrounding diet containing $100 \mathrm{mg} 3-\mathrm{NOP} / \mathrm{kg} \mathrm{DM}$ for $7 \mathrm{~d}$. Once assigned to the $\mathrm{CH}_{4}$ production study, they were provided a 21-d adaptation (adaptation phase) during which they continued to receive the diet containing $150 \mathrm{mg} 3-\mathrm{NOP} / \mathrm{kg} \mathrm{DM}$. The adaptation phase allowed the animals to become familiar with the $\mathrm{CH}_{4}$ emission monitoring system described below. Following the adaptation phase, the study was conducted in three 28-d phases, with the concentration of 3-NOP in the basal diet increased in each phase: low $(150 \mathrm{mg} / \mathrm{kg} \mathrm{DM})$ in Phase 1 , medium (175 mg/kg DM) in Phase 2, and high (200 mg/kg DM, final dose) in Phase 3. An additional 2 weeks of adaptation was added between Phases 1 and 2, during which barley silage was 
replaced with corn silage due to a shortage of barley silage at the feedlot. Animals were fed twice a day $(0900$ and 1,500 h) for ad libitum intake (5\% orts). Orts were removed and weighed weekly. Because individual animal data were obtained for gas measurements and DMI, the experimental/observational unit was the animal (Bello and Renter, 2017).

\section{Emission Measurements}

Methane and $\mathrm{H}_{2}$ were measured using the GEM system. Each week the two pens of animals were rotated, such that each pen of cattle had access to the GEM system for 1 week, every second week. This approach controlled any possible pen effects and has been implemented previously (Alemu et al., 2019, 2020). Within a phase, each pen had access to the system for two 7-d periods.

The GEM system allows free movement of animals (in and out of the system) and gasses are measured only when the animal's head is in the "head chamber" unit as determined by the proximity sensor. The system is equipped with a radio-frequency reader that identifies the electronic ear tag of each animal. During a visit to the GEM system, animals are provided with pellets from an overhead hopper (as bait). The interval between pellet drops was set to $35 \mathrm{~s}$ to keep the animals in the hood for sufficient time (3-7 min) to obtain a full measurement. Maximum daily pellet drops per animal (36 drops, 6 drops/visit) was set to restrict the amount of pellet consumption. The total amount of pellet DM consumed per animal per day was added to the animal's intake of basal diet DM from the GrowSafe bunks, to calculate total DMI. Animals could visit the system any time but they were eligible for pellet drops only during six visits that were spaced a minimum of $4 \mathrm{~h}$ apart during each 24 -h cycle. Thus, animals were required to wait $4 \mathrm{~h}$ before getting their next pellet drop. The pellet was composed of ground barley, canola meal and oil, dried molasses and salt with a composition of (\% of DM): 14.4 \pm 1.10 crude protein $(\mathrm{CP}), 22.0 \pm 1.62$ neutral detergent fiber (NDF), $8.23 \pm 0.48$ acid detergent fiber (ADF), and $20.5 \pm 0.29$ $\mathrm{MJ} / \mathrm{kg}$ gross energy.

Once the animal's head is in the hood of the GEM system, air is drawn past the nose and mouth of the animal at about 26-40 L/s into the collection pipe. The system measures $\mathrm{CH}_{4}, \mathrm{CO}_{2}$, and $\mathrm{H}_{2}$ continuously together with air flow, temperature, atmospheric pressure, and relative humidity. Each gas is analyzed by a separate non-dispersive infrared analyzer, which was calibrated weekly using a zero (semipure nitrogen) and span $\mathrm{CH}_{4}$ and $\mathrm{CO}_{2}$ gases, with nitrogen as the balance gas. The purpose of the calibration was to define sensor responses to known concentration of gasses. Five times during the experiment, the air flux sensor was calibrated by releasing a gravimetrically determined quantity of $\mathrm{CO}_{2}$ into the system using a 90 -g prefilled $\mathrm{CO}_{2}$ cylinder for $3 \mathrm{~min}$ (at least three times). The amount released was compared to the calculated capture $\left(96.7 \% \mathrm{CO}_{2}\right.$ recovery, $\left.\mathrm{SD}=4.6, n=5\right)$. To maintain a consistent airflow rate between 27 and $40 \mathrm{~L} / \mathrm{s}$ in the collection tube (Velazco et al., 2016), the air filter was cleaned and changed regularly (every 3-5 days).

To calculate mass flux of $\mathrm{CH}_{4}$, the measured increase in concentration in the animal's breath relative to that in the ambient (background) air was multiplied by the measured air flow rate, and then the ideal gas law was applied.

$$
\mathrm{CH}_{4-\text { volume }}=F_{c} * \frac{1}{C_{R}} * \sum_{t p}\left[\Delta t *\left(\mathrm{CH}_{4-\text { average }}-\mathrm{CH}_{4-\text { background }}\right) * Q_{\text {air }}\right]
$$

Where, $F_{C}$ is the dimensional factor; $1 / C_{R}$ is the capture rate of emissions into collection pipes determined using a tracer (\%); $\Delta \mathrm{t}$ is time period over which emissions are measured (1 s); $\mathrm{CH}_{4-\text { average }}$ is average concentration of $\mathrm{CH}_{4}(\%) ; \mathrm{CH}_{4}$-background is background concentration of $\mathrm{CH}_{4}(\%)$; and $\mathrm{Q}_{\text {air }}$ is air flow rate (flow per unit time). Once the volume flow rates of $\mathrm{CH}_{4}$ are determined, the mass flux is determined by applying the ideal gas law. Daily $\mathrm{CH}_{4}$ emission for individual animals was calculated over the 7-d by aggregating and averaging the visit fluxes by time of day (for each 4 -h block). Within each phase, only cattle with $\geq 10$ useful/good visits with visits in at least five of the six 4-h time blocks were used in the analysis to ensure that the full diurnal cycle of emission was represented, as $\mathrm{CH}_{4}$ emissions fluctuate over the 24-h cycle (Gunter and Bradford, 2015; Manafiazar et al., 2016). Hydrogen was calculated using an "arithmetic averaging method," which is a straight averaging of the visit fluxes (Manafiazar et al., 2016).

\section{Sample Collection and Analysis}

Feed ingredients and the basal diet offered were sampled every day during the $\mathrm{CH}_{4}$ emission study and composited by week for further chemical analyses. A sample of pellets from the GEM system was collected every 2 weeks for chemical analysis. The chemical composition of ingredients and basal diet are presented in Table 1. Feed ingredients, basal diet and pellet samples were dried at $55^{\circ} \mathrm{C}$ for $72 \mathrm{~h}$ in a forced air oven for DM determination. Dried samples were ground in a Wiley mill (Thomas Scientific, Swedesboro, NJ) through a 1-mm screen. Analytical DM content of the ground samples was determined by drying at $135^{\circ} \mathrm{C}$ for $2 \mathrm{~h}$ (method 930.15; AOAC, 2016). The NDF and ADF contents were determined sequentially using an Ankom A200 fiber analyzer (Ankom Technology, Macedon, NY), with heat-stable amylase and sodium sulfite used for NDF analysis. Gross energy concentration was determined using a bomb calorimeter (model E2k, CAL2k, Johannesburg, South Africa). Samples ground through a 1-mm screen were reground using a ball grinder (Mixer Mill MM2000; Retsch GmbH, Haan, Germany) before determination of nitrogen content. The nitrogen content (CP $=$ nitrogen $\times 6.25$ ) was determined by flash combustion with gas chromatography and thermal conductivity detection (Carlo Erba Instruments, Milan, Italy). Ground, dried samples of the basal diet were shipped to DSM Nutritional Products (Basel, Switzerland) for measurement of 3-NOP concentration using HPLC (method AP.227089.01) and propanediol mononitrate as a reference standard.

\section{Statistical Analysis}

For the large pen study, the animal performance data (DMI, ADG and G:F) for each pen were analyzed using the GLIMMIX procedure of SAS (SAS Inst. Inc., Cary, NC) where experimental group (control, 3-NOP) was considered a fixed effect and replicate (1-8) a random effect. Morbidity and mortality data 
TABLE 2 | Performance of beef steers fed a backgrounding basal diet supplemented with and without 3-nitrooxypropanol (3-NOP; 200 mg/kg DM; $n=8$ pens/treatment).

\begin{tabular}{lcccc}
\hline Item & Control & 3-NOP & SEM & P-value \\
\hline Start BW, kg & 283 & 282 & 3.01 & 0.62 \\
End BW, kg & 422 & 421 & 6.11 & 0.70 \\
Total weight gained, kg & 139 & 139 & 3.74 & 0.87 \\
ADG, kg/d & 1.30 & 1.30 & 0.06 & 0.87 \\
DMl, kg/d & 8.07 & 7.86 & 0.26 & 0.06 \\
G:F & 0.16 & 0.17 & 0.003 & 0.06 \\
\hline
\end{tabular}

aG:F = Gain:Feed ratio calculated as kg live weight gain/kg dry matter intake.

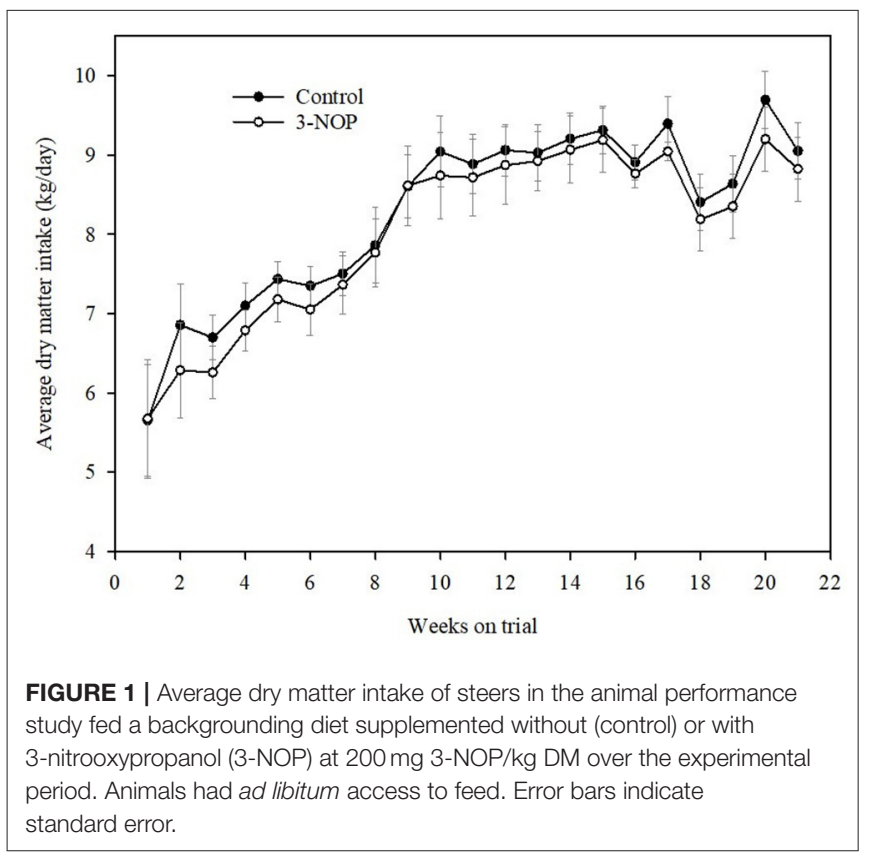

were analyzed using the GENMOD procedure in SAS where experimental group was considered a fixed effect and pen within replicate as a clustering effect.

For the small pen $\mathrm{CH}_{4}$ study, DMI and gas data for each animal were analyzed by phase and overall using the MIXED procedure of SAS. Within phase, the model included experimental group (control, 3-NOP), week (1-4 for DMI, 1 and 2 for gases), and their interaction as fixed effects, with week considered as a repeated effect in the model. KenwardRoger's option was used in the model statement to estimate denominator degrees of freedom. Best time-series covariance structure was selected on the basis of the lowest Akaike and Bayesian information criteria and compound symmetry was used. Residual plots were used to check the validity of the underlying statistical assumptions of homogeneity of variances and normality. Statistical significance was declared at $P<0.05$ and trends are discussed at $P \leq 0.10$.

\section{RESULTS}

\section{Animal Performance Study}

Inclusion of 3-NOP tended to decrease DMI (2.6\%, $P=0.06)$, without affecting total weight gain $(P=0.87)$ or $\mathrm{ADG}(P=$
TABLE 3 | Mortality and post-allocation morbidity percentages for beef steers fed a backgrounding basal diet supplemented with and without 3-nitrooxypropanol (3-NOP; 200 mg/kg DM; $n=8$ pens/treatment).

\begin{tabular}{|c|c|c|c|}
\hline Item & Control & 3-NOPa & $P$-value \\
\hline \multicolumn{4}{|l|}{ Morbidity, \% } \\
\hline $\begin{array}{l}\text { Initial undifferentiated } \\
\text { treatment of fever }\end{array}$ & 2.24 & 2.25 & 0.99 \\
\hline $\begin{array}{l}\text { First undifferentiated } \\
\text { fever relapse } \\
\text { treatment }^{\mathrm{b}}\end{array}$ & 17.63 & 28.57 & 0.72 \\
\hline $\begin{array}{l}\text { Initial treatment } \\
\text { without fever }\end{array}$ & 4.05 & 3.38 & 0.64 \\
\hline $\begin{array}{l}\text { First relapse } \\
\text { treatment without } \\
\text { feverc }^{c}\end{array}$ & 10.82 & 15.12 & 0.07 \\
\hline $\begin{array}{l}\text { Chronicity (chronic } \\
\text { disease, all causes) }\end{array}$ & 0.69 & 0.69 & 0.99 \\
\hline Wastage $^{d}$ & 0.34 & 0.64 & 0.13 \\
\hline \multicolumn{4}{|l|}{ Mortality, \% } \\
\hline Overall & 0.49 & 0.69 & 0.32 \\
\hline Respiratory disease & 0.15 & 0.20 & 0.67 \\
\hline $\begin{array}{l}\text { Lesions consistent } \\
\text { with Histophilus } \\
\text { Somni infection }\end{array}$ & 0.20 & 0.10 & 0.33 \\
\hline Metabolic disease & 0.14 & 0 & NA \\
\hline Lameness & 0 & 0.05 & NA \\
\hline Other & 0 & 0.35 & NA \\
\hline
\end{tabular}

aNo health issues was observed for animals used in the methane production study in small pens.

${ }^{b}$ Number of animals treated for first undifferentiated relapse following allocation divided by the number of animals treated for initial undifferentiated relapse.

${ }^{c}$ Number of animals treated for first no-fever relapse following allocation divided by the number of animals treated for initial no-fever.

${ }^{d}$ Wastage is the number of animals with chronic disease (all causes) that did not die divided by the number of animals allocated.

NA, not available.

0.87) (Table 2). As a result, G:F tended to improve $(2.5 \% ; P$ $=0.06)$ by feeding 3 -NOP compared with the control $(0.16 \mathrm{~kg}$ liveweight gain $/ \mathrm{kg} \mathrm{DMI})$. The pattern of DMI over the study showed that the cattle fed 3-NOP generally had lower intake during the first 6 weeks of the feeding period (Figure 1). There were no differences in morbidity or mortality detected between the experimental groups (Table 3). However, there was a tendency for animals fed 3-NOP to have a slightly greater percentage $(P=0.07)$ of treatment of animals for relapse without a fever.

\section{Methane Production Study}

The measured concentrations of 3-NOP in the basal diet offered in the GrowSafe bunks and calculated concentrations in the total feed consumed (basal diet plus pellet offered in the GEM system) during the study are presented in Table 4. Recovery of 3-NOP in the basal diet averaged $105.7 \%$, ranging from 89.7 to $120.7 \%$, which is within an acceptable range for most feed additives. Calculated concentration of 3-NOP in the total DMI, which accounts for intake of the basal diet and the pellets offered in the GEM system, was $124.6,192.8$, and $226.8 \mathrm{mg} / \mathrm{kg}$ DM for the low, 
TABLE 4 | Targeted and measured concentration of 3-nitrooxypropanol (3-NOP) in the diets fed during the methane emission measurement study $(n=4$ observations/phase, mean $\pm \mathrm{SD})$.

\begin{tabular}{|c|c|c|c|c|}
\hline \multirow[t]{2}{*}{ Item $^{a}$} & \multicolumn{4}{|c|}{ Phase } \\
\hline & Adaptation $^{\mathrm{b}}$ & Low & Medium & High \\
\hline $\begin{array}{l}\text { Target concentration in basal diet, mg 3-NOP/kg } \\
\text { DM }\end{array}$ & 150 & 150 & 175 & 200 \\
\hline $\begin{array}{l}\text { Measured concentration in basal diet, } \\
\mathrm{mg} 3-\mathrm{NOP} / \mathrm{kg} \mathrm{DM}\end{array}$ & $141.1 \pm 11.8$ & $134.5 \pm 25.4$ & $207.2 \pm 13.6$ & $241.4 \pm 8.3$ \\
\hline Recovery, \% ${ }^{c}$ & 94.1 & 89.7 & 118.4 & 120.7 \\
\hline $\begin{array}{l}\text { Calculated concentration in total diet consumed, } \\
\mathrm{mg} 3-\mathrm{NOP} / \mathrm{kg} \mathrm{DM}\end{array}$ & 130.8 & 124.6 & 192.8 & 226.8 \\
\hline Intake, g 3-NOP/d & $1.11 \pm 0.167$ & $1.27 \pm 0.291$ & $2.25 \pm 0.266$ & $2.75 \pm 0.372$ \\
\hline
\end{tabular}

${ }^{a}$ Basal diet was provided in the GrowSafe feed bunks and total diet refers to basal diet + pellets provided in the GreenFeed system. 3-NOP concentration in the control diet was zero. ${ }^{b}$ Animals adapted to 3-NOP and the GreenFeed emission monitoring system for $28 \mathrm{~d}$.

${ }^{C}$ Calculated as: (measured 3-NOP concentration/target concentration) $\times 100$.

${ }^{d}$ Daily 3-NOP intake was calculated from the measured concentration in the basal diet and the measured total DMI of each animal.

TABLE 5 | Dry matter intake (DMl, kg/d; basal diet, pellet, and total) for beef steers $(n=25)$ during the enteric $\mathrm{CH}_{4}$ emission measurement study.

\begin{tabular}{|c|c|c|c|c|}
\hline Phase $^{a}$ & Control & 3-NOP & SEM & $P$-value \\
\hline \multicolumn{5}{|l|}{ Phase 1: Low dose } \\
\hline Total diet ${ }^{b}$ & 9.64 & 9.38 & 0.25 & 0.31 \\
\hline Basal diet (GrowSafe system) & 9.37 & 9.02 & 0.27 & 0.19 \\
\hline Pellet (GreenFeed system) & 0.27 & 0.36 & 0.06 & 0.10 \\
\hline \multicolumn{5}{|l|}{ Phase 2: Medium dose } \\
\hline Total $\operatorname{diet}^{b}$ & 11.55 & 10.88 & 0.27 & 0.02 \\
\hline Basal diet (GrowSafe system) & 11.25 & 10.48 & 0.28 & 0.01 \\
\hline Pellet (GreenFeed system) & 0.30 & 0.39 & 0.04 & 0.04 \\
\hline \multicolumn{5}{|l|}{ Phase 3: High dose } \\
\hline Total $\operatorname{diet}^{b}$ & 12.06 & 11.35 & 0.37 & 0.06 \\
\hline Basal diet (GrowSafe system) & 11.76 & 10.98 & 0.39 & 0.05 \\
\hline Pellet (GreenFeed system) & 0.30 & 0.37 & 0.04 & 0.12 \\
\hline \multicolumn{5}{|l|}{ Overall: Phases 1-3 } \\
\hline Total $\operatorname{diet}^{b}$ & 10.43 & 9.87 & 0.23 & 0.02 \\
\hline Basal diet (GrowSafe system) & 10.16 & 9.51 & 0.25 & 0.01 \\
\hline Pellet (GreenFeed system) & 0.27 & 0.36 & 0.05 & 0.07 \\
\hline
\end{tabular}

Steers were fed a backgrounding basal diet without (control) or with increasing doses of 3-nitrooxypropanol (3-NOP).

${ }^{a}$ Low dose $=150 \mathrm{mg} 3-\mathrm{NOP} / \mathrm{kg}$ DM, medium dose $=175 \mathrm{mg} 3-\mathrm{NOP} / \mathrm{kg} \mathrm{DM}$, high dose $=200 \mathrm{mg} 3-\mathrm{NOP} / \mathrm{kg}$ DM. 3-Nitrooxypropanol was added only to the basal diet.

${ }^{b}$ Total dietary DMI is the sum of DMI of the basal diets delivered in the GrowSafe system and DMI of the pellet delivered in the GEM system.

medium and high doses respectively. Average daily consumption of 3-NOP increased with inclusion rate as expected, $1.27 \mathrm{~g} / \mathrm{d}$ for the low, $2.25 \mathrm{~g} / \mathrm{d}$ for medium, and $2.75 \mathrm{~g} / \mathrm{d}$ for the high dose.

Dry matter intake for the low (phase 1), medium (phase 2), and high (phase 3 ) doses of 3-NOP is reported in Table 5. On average, total DMI was lower $(P=0.02)$ by $5.3 \%$ for 3 -NOP as compared to the control treatment $(10.43 \mathrm{~kg} / \mathrm{d})$. Intake was not affected by the low dose but was $5.8 \%$ less for the medium dose compared with control $(11.55 \mathrm{~kg} / \mathrm{d})$ and $5.9 \%$ lower for the high dose compared with control $(12.06 \mathrm{~kg} / \mathrm{d})$. For animals visiting the GEM system, average pellet consumption tended to be greater $(P=0.07)$ for the 3 -NOP group $(0.36 \mathrm{~kg} / \mathrm{d})$ relative to the control group $(0.27 \mathrm{~kg} / \mathrm{d})$.
Of the 25 animals assigned to each treatment, on average, $76 \%$ of animals (ranging between 60 and 84\%) for control and $88 \%$ of animals (ranging between 80 and $92 \%$ ) for 3-NOP visited the GEM system (Table 6). Over the study period, the average total visits were 1,156 and 1,556 for control and 3-NOP groups, respectively. The number of weekly visits to the GEM system and the number of 4-h blocks in which visits occurred were not affected by treatment group in any phase $(P \geq 0.20)$. The visits to the GEM system were relatively consistent throughout the 24-h period, with the exception of between 0300 and $0400 \mathrm{~h}$ (Figure 2). On average, each visit to the GEM system lasted slightly more than $4 \mathrm{~min}$ and did not differ $(P \geq 0.48)$ between treatment groups (Table 6). 
TABLE 6 | Visits ${ }^{a}$ to the GreenFeed emission monitoring (GEM) system for beef steers fed a backgrounding basal diet without (control) or with increasing doses of 3-nitrooxypropanol (3-NOP).

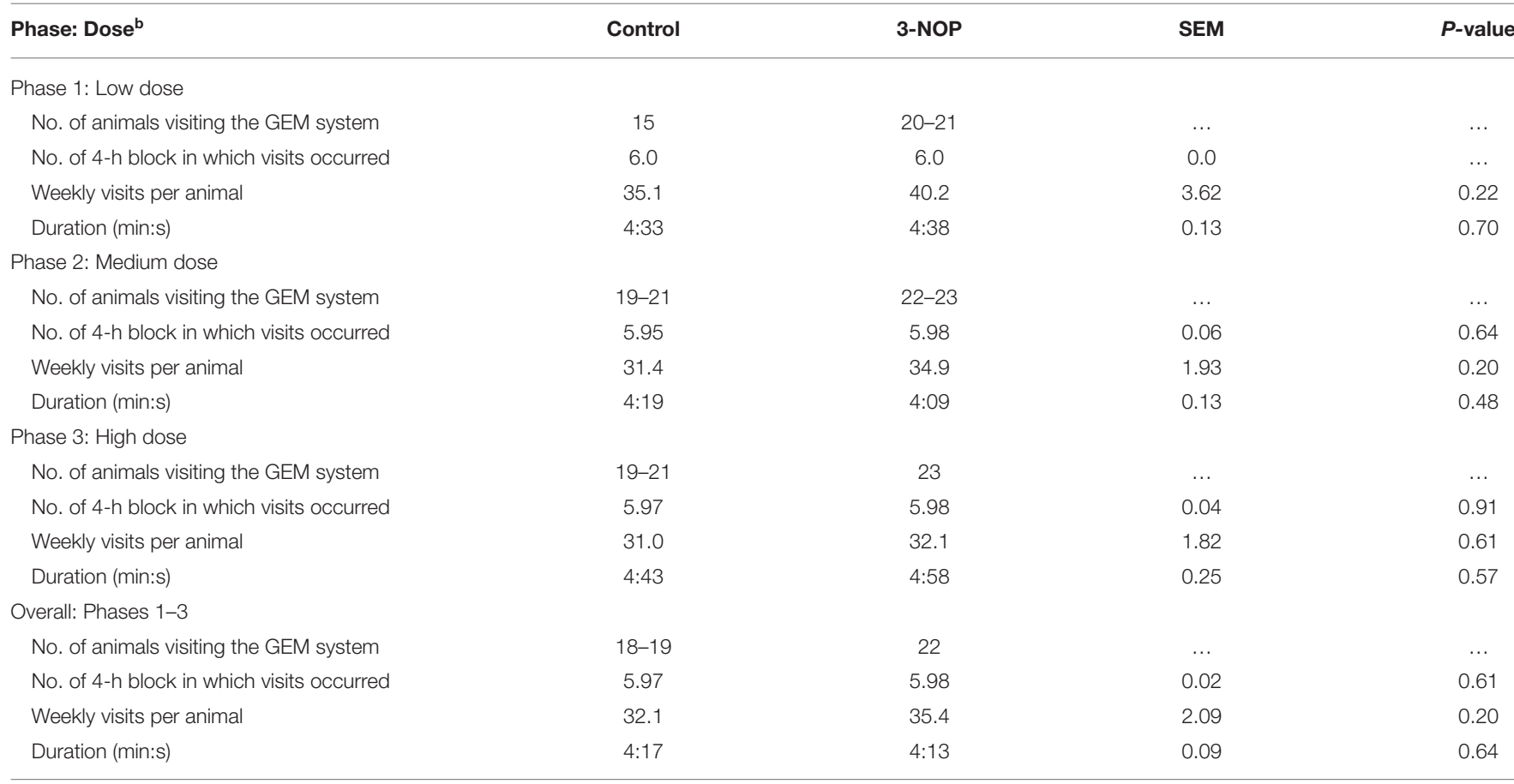

aVisits were compiled into six 4-h blocks corresponding to time of day. Only "useful/good" visits of at least 3-min were used to calculate weekly visits per animal (Arthur et al., 2017: Beck et al., 2018). Only animals with $\geq 10$ "useful/good" weekly visits, with visits in at least 5 of the six 4-h time blocks were selected for final analysis.

${ }^{b}$ Low dose $=150 \mathrm{mg} 3-\mathrm{NOP} / \mathrm{kg} \mathrm{DM}$, medium dose $=175 \mathrm{mg} 3-\mathrm{NOP} / \mathrm{kg}$ DM, high dose $=200 \mathrm{mg}$ 3-NOP $/ \mathrm{kg}$ DM. 3-Nitrooxypropanol was added only to the basal diet.

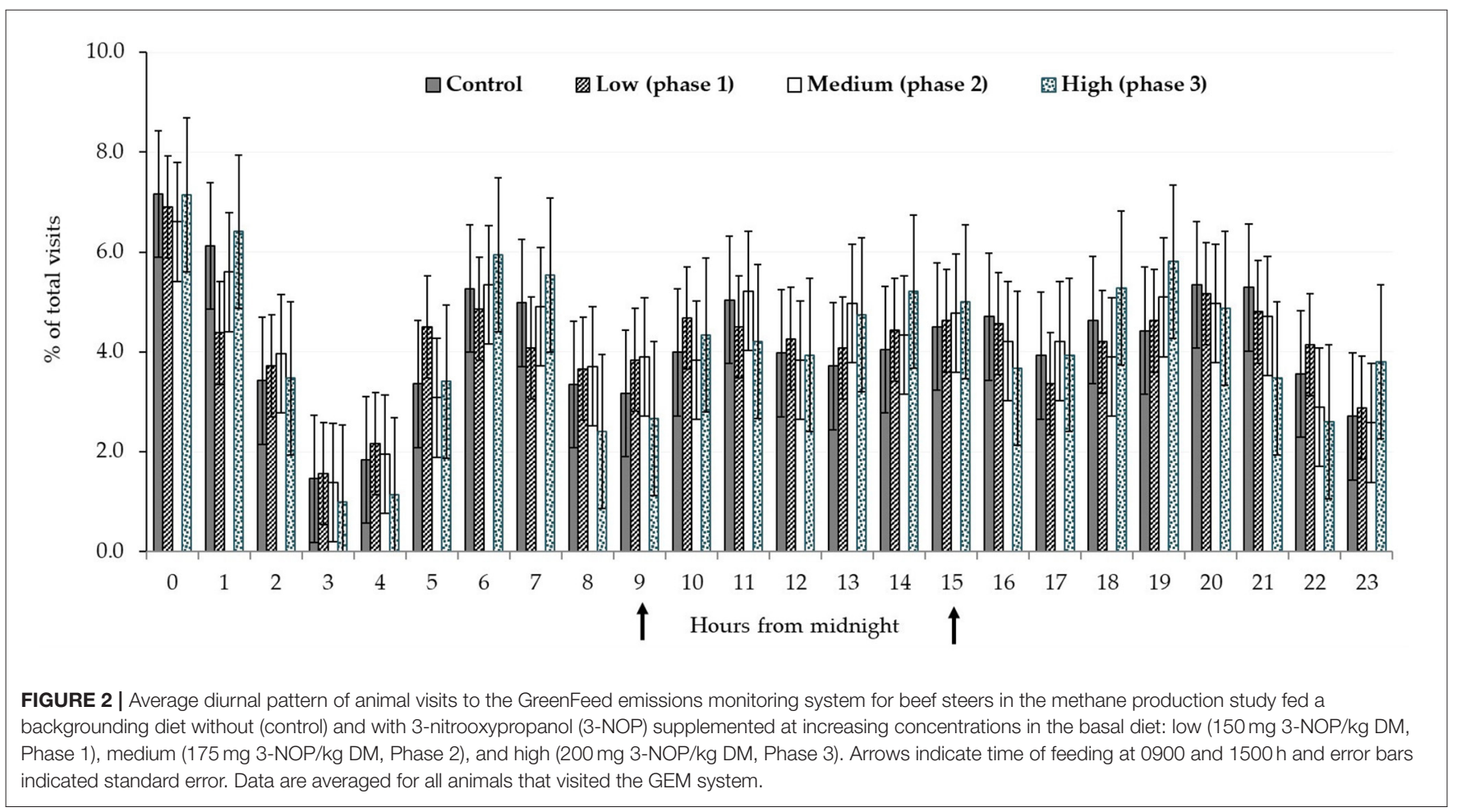


TABLE 7 | Enteric methane $\left(\mathrm{CH}_{4}\right)$ and hydrogen $\left(\mathrm{H}_{2}\right)$ emissions for beef steers fed a backgrounding basal diet without (control) or with increasing doses of 3-nitrooxypropanol (3-NOP).

\begin{tabular}{|c|c|c|c|c|c|c|}
\hline Phase: Dose ${ }^{a}$ & Emission $^{b}$ & Units & Control & 3-NOP & SEM & $P$-value \\
\hline \multirow[t]{5}{*}{ Phase 1: Low dose } & $\mathrm{CH}_{4}$ & $g / d$ & 224.8 & 185.7 & 8.04 & 0.01 \\
\hline & & $\mathrm{g} / \mathrm{kg}$ total DMl & 23.76 & 18.97 & 1.16 & 0.01 \\
\hline & & $\%$ gross energy intake & 5.99 & 4.85 & 0.30 & 0.01 \\
\hline & $\mathrm{H}_{2}$ & $g / d$ & 0.37 & 1.29 & 0.09 & $<0.001$ \\
\hline & & $\mathrm{g} / \mathrm{kg}$ total DMl & 0.04 & 0.14 & 0.01 & $<0.001$ \\
\hline \multirow[t]{5}{*}{ Phase 2: Medium dose } & $\mathrm{CH}_{4}$ & $g / d$ & 259.7 & 184.9 & 6.18 & $<0.001$ \\
\hline & & $\mathrm{g} / \mathrm{kg}$ total DMl & 22.33 & 16.64 & 0.61 & $<0.001$ \\
\hline & & $\%$ gross energy intake & 5.82 & 4.43 & 0.16 & $<0.001$ \\
\hline & $\mathrm{H}_{2}$ & $g / d$ & 0.41 & 1.64 & 0.08 & $<0.001$ \\
\hline & & $\mathrm{g} / \mathrm{kg}$ total DMl & 0.03 & 0.14 & 0.01 & $<0.001$ \\
\hline \multirow[t]{5}{*}{ Phase 3: High dose } & $\mathrm{CH}_{4}$ & $g / d$ & 275.7 & 198.4 & 8.51 & $<0.001$ \\
\hline & & $\mathrm{g} / \mathrm{kg}$ total DMl & 22.40 & 17.68 & 0.62 & $<0.001$ \\
\hline & & \% gross energy intake & 5.88 & 4.80 & 0.17 & 0.002 \\
\hline & $\mathrm{H}_{2}$ & $g / d$ & 0.39 & 1.55 & 0.06 & $<0.001$ \\
\hline & & $\mathrm{g} / \mathrm{kg}$ total DMl & 0.03 & 0.13 & 0.01 & $<0.001$ \\
\hline \multirow[t]{5}{*}{ Overall: Phases 1 to 3} & $\mathrm{CH}_{4}$ & $g / d$ & 255.2 & 189.6 & 6.91 & 0.001 \\
\hline & & $\mathrm{g} / \mathrm{kg}$ total DMl & 22.49 & 17.61 & 0.64 & 0.001 \\
\hline & & $\%$ gross energy intake & 5.89 & 4.67 & 0.16 & 0.001 \\
\hline & $\mathrm{H}_{2}$ & $g / d$ & 0.39 & 1.50 & 0.05 & $<0.001$ \\
\hline & & $\mathrm{g} / \mathrm{kg}$ total DMl & 0.03 & 0.14 & 0.01 & $<0.001$ \\
\hline
\end{tabular}

DMI, dry matter intake.

${ }^{a}$ Low dose $=150 \mathrm{mg} 3-\mathrm{NOP} / \mathrm{kg}$ DM, medium dose $=175 \mathrm{mg} 3-\mathrm{NOP} / \mathrm{kg}$ DM, high dose $=200 \mathrm{mg}$ 3-NOP $/ \mathrm{kg}$ DM. 3-Nitrooxypropanol was added only to the basal diet.

bOnly animals with $\geq 10$ "useful/good" weekly visits, with visits in at least 5 of the six 4-h time blocks were selected for $\mathrm{CH}_{4}$ analysis.

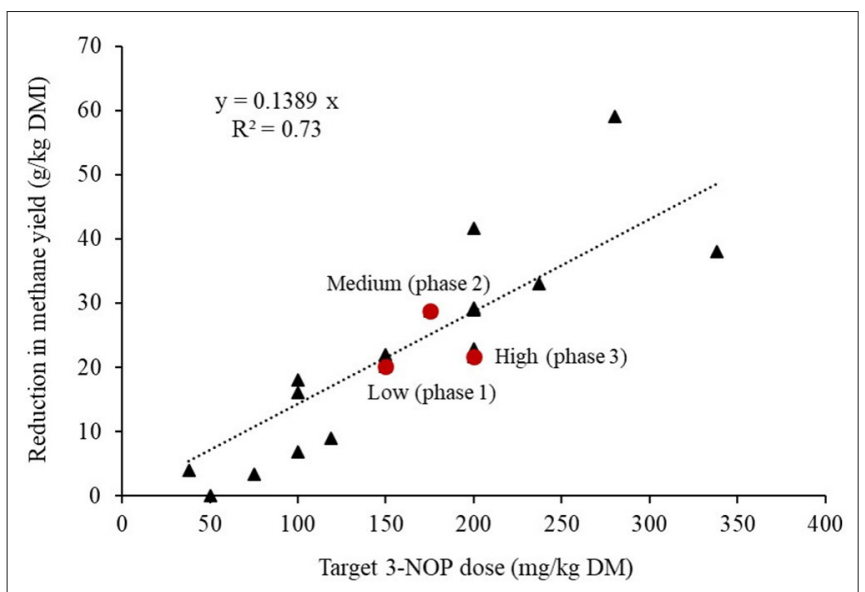

FIGURE 3 | Reduction in methane yield $\left(\mathrm{g} \mathrm{CH}_{4} / \mathrm{kg}\right.$ dry matter intake, DMI) observed in the study (indicated by closed circles) compared with the published literature (indicated by closed triangles) for feedlot cattle fed high-forage backgrounding diets. The linear regression line is fitted through all the data using an intercept of zero. Literature studies were Alemu et al. (present study, unpublished), Romero-Perez et al. (2014), Vyas et al. (2016a,b, 2018), Smith (2017), Martinez-Fernandez et al. (2018), and Kim et al. (2019).

Methane and $\mathrm{H}_{2}$ production (g/d) and yield (g/kg DMI) for the low (phase 1), medium (phase 2), and high (phase 3) doses of 3-NOP are reported in Table 7. Methane production (g/d) decreased $(P \leq 0.01)$ by $17.4,28.8$, and $28.1 \%$ for the low, medium and high doses of 3-NOP, respectively, compared with control, averaging $255.2 \mathrm{~g} / \mathrm{d}$. Thus, over the entire study, 3-NOP reduced $\mathrm{CH}_{4}$ production by an average of $25.7 \%$ ( $P=$ 0.001). Methane yield ( $\mathrm{g} / \mathrm{kg} \mathrm{DMI})$ followed a similar pattern with decreases of $17.2,25.7$, and $21.3 \%$ for low, medium and high doses of 3-NOP, respectively, with a $21.7 \%$ decrease overall $(P=0.001)$. When $\mathrm{CH}_{4}$ energy was expressed as percentage of gross energy intake, feeding 3-NOP decreased emissions by $19.1,23.9$, and $18.4 \%$ for the three doses respectively, and by $20.8 \%$ overall $(P \leq 0.01)$. The reduction in $\mathrm{CH}_{4}$ yield by phase is compared with previous literature for beef cattle fed high-forage diets in Figure 3. The average diurnal pattern of $\mathrm{CH}_{4}$ emissions during the study by treatment is presented in Figure 4A.

With the decrease in $\mathrm{CH}_{4}$ production due to 3-NOP, there was a concomitant increase in $\mathrm{H}_{2}$ production, which increased from $0.39 \mathrm{~g} / \mathrm{d}$ for control to $1.50 \mathrm{~g} / \mathrm{d}(P<0.001)$ for 3 -NOP overall. The increases in $\mathrm{H}_{2}$ emissions were consistent within each phase. The average diurnal pattern of $\mathrm{H}_{2}$ production during the study by treatment is presented in Figure 4B.

\section{DISCUSSION}

\section{Animal Performance and Health}

Two previous controlled research studies conducted in small pens examined the effects of including 3-NOP in high-forage backgrounding diets on animal performance (Vyas et al., 2016a, 2018). In a 105-day study, Vyas et al. (2016a) reported that 


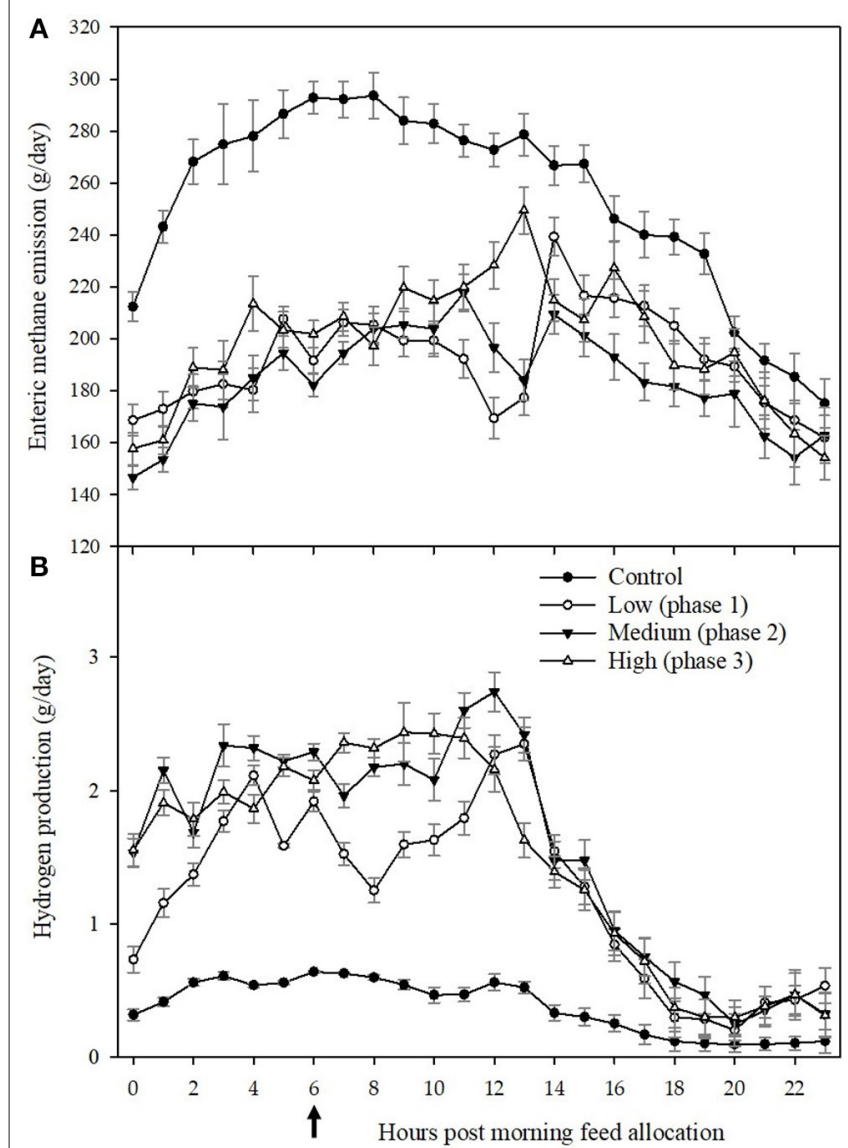

FIGURE 4 | Mean hourly enteric methane emissions (A) and hydrogen production (B) from feedlot steers in the methane production study fed a backgrounding diet without (control) and with 3-nitrooxypropanol (3-NOP) supplemented at increasing concentrations in the basal diet: low $(150 \mathrm{mg}$ 3-NOP/kg DM, Phase 1), medium (175 mg 3-NOP/kg DM, Phase 2), and high (200 mg 3-NOP/kg DM, Phase 3). Animals were fed twice a day at $0900 \mathrm{~h}$ (indicated as 0) and $1500 \mathrm{~h}$ (indicated by the arrow), and error bars indicated standard error.

inclusion of 3-NOP (200 mg/kg DM) reduced DMI by $8.0 \%$ and increased G:F by 7.7\%. Using the same concentration of 3-NOP, Vyas et al. (2018) reported 9.2\% reduction in DMI and 6.5\% improvement in G:F for beef steers relative to control. Several factors including improved energy status of the animal as a result of decreased energy loss in the form of $\mathrm{CH}_{4}$ and a shift in metabolic precursors may account for the observed reduction in DMI and improved efficiency (Lee et al., 2019; Alemu et al., 2020). The present study is the first to examine the effects of 3 NOP in a commercial feedlot setting in which animals were fed a backgrounding diet and group-housed in large pens that are representative of the scale that exists in commercial production scenarios, which may create considerable competition among animals at the feed bunk. For beef cattle fed forage-based diets, Custodio et al. (2017) reported that feeding behavior of cattle can be influenced by housing system (individual vs. collective pen). Before beef producers use 3-NOP to mitigate $\mathrm{CH}_{4}$ emissions they need information on the health and performance of animals fed 3-NOP in commercial conditions, in addition to efficacy of $\mathrm{CH}_{4}$ reduction.

Using a 3-NOP concentration of $200 \mathrm{mg} / \mathrm{kg} \mathrm{DM}$ in the performance study reduced DMI by $2.6 \%$, which was considerably less than that observed in previous small-scale research studies (Vyas et al., 2016a, 2018). The relatively small decrease in DMI of animals in the performance study (2.6\%) also contrasts with the observed 5.9\% reduction in DMI of animals in the $\mathrm{CH}_{4}$ study, when fed the high dose $(200 \mathrm{mg} 3-\mathrm{NOP} / \mathrm{kg}$ $\mathrm{DM})$. The greater decline in DMI of cattle fed 3-NOP in smallpen studies does not appear to be due to lack of adaptation of animals to 3-NOP, because in the present studies the animals were gradually transitioned to 3-NOP. Furthermore, during $\mathrm{CH}_{4}$ measurements, for which the reduction in DMI was greatest, the transition was gradual with use of an adaption period followed by a phased step-up. As DMI relative to BW was similar for the control animals in both the performance and $\mathrm{CH}_{4}$ studies, the reasons for the greater decline in DMI of animals fed 3-NOP in the small pens are not clear. It is possible that the differing response is related to differences in competition at the feed bunk caused by the type of feeder (long trough in the large pens vs. feed bins in the small pens), feed bunk management (slick-bunk vs. ad lib, Schwartzkopf-Genswein et al., 2003; Schutz et al., 2011) and the frequency of feed allocation (top-up throughout the day in large pens vs. 2-times daily in small pens). The smaller decline in DMI observed in the animal production study may account for the relatively smaller $(2.5 \%)$ improvement in feed conversion efficiency compared with the $6.5-7.7 \%$ improvement observed in previously reported small-pen studies (Vyas et al., 2016a, 2018).

Animal health in response to 3-NOP supplementation has not been previously documented. Although the finding of no increased risk of mortality and morbidity in cattle fed 3-NOP has important implications for future use of the product by commercial feedlots, the observed tendency for the treatment of animals with relapse without a fever requires further investigation.

\section{Gaseous Emissions}

A meta-analysis of data from 11 experiments (Dijkstra et al., 2018) indicated that with a mean inclusion rate of $123 \mathrm{mg}$ 3-NOP/kg DM, enteric $\mathrm{CH}_{4}$ production $(\mathrm{g} / \mathrm{d})$ and yield $(\mathrm{g} / \mathrm{kg}$ $\mathrm{DM}$ ) were reduced by 22.2 and $17.1 \%$, respectively, in beef cattle fed a range of diets. Those authors also indicated that the effect of 3-NOP on enteric $\mathrm{CH}_{4}$ production was positively associated with dose and inversely associated with diet NDF concentration. Thus, the response to $3-\mathrm{NOP}$ at a particular level of 3-NOP would be expected to be less for backgrounded cattle fed higher fiber diets compared with finishing cattle fed grainbased diets. The reduction in $\mathrm{CH}_{4}$ yield observed in the present study (decrease of 20.1, 25.5, and $21.1 \%$ for low, medium and high doses of 3-NOP; $21.7 \%$ decrease overall) is consistent with the previous literature (Figure 3), although a linear response to 3NOP concentration was not observed in the present study. When examined over nine beef studies (including the present study) with 17 treatment means of cattle fed high-forage diets $(\geq 60 \%$ forage DM), the linear response to targeted dietary concentration 
of 3-NOP is: Reduction in $\mathrm{CH}_{4}$ yield $=0.1389 \times \mathrm{mg} 3-\mathrm{NOP} / \mathrm{kg}$ $\mathrm{DM}\left(R^{2}=0.73\right)$. The reason for the lack of linear response to 3-NOP dose in the present study is not clear. One factor may be the study design wherein each dose of 3-NOP was evaluated sequentially, rather than simultaneously, and hence the cattle were exposed to 3-NOP for a differing number of days at each dose, making it difficult to compare the animal responses across dose.

Methane is the largest sink of $\mathrm{H}_{2}$ in the rumen. When methanogenesis is inhibited gaseous $\mathrm{H}_{2}$ can accumulate (Hristov et al., 2015; Vyas et al., 2018), as was observed in the present study where $\mathrm{H}_{2}$ was on average $1.50 \mathrm{~g} / \mathrm{d}$ for the 3-NOP group compared with $0.39 \mathrm{~g} / \mathrm{d}$ for control cattle. Although the release of gaseous $\mathrm{H}_{2}$ represents an inefficiency of energy utilization, the loss of energy as $\mathrm{H}_{2}$ was only $4 \%$ of the energy potentially available from the decrease in $\mathrm{CH}_{4}$ production $\left(65.7 \mathrm{~g} \mathrm{CH}_{4}, 55\right.$ $\mathrm{kJ} / \mathrm{g}$ vs. $1.11 \mathrm{~g} \mathrm{H}_{2}, 142 \mathrm{~kJ} / \mathrm{g}$ ). In terms of reducing equivalents, 65.7 $\mathrm{g} / \mathrm{d}$ of spared $\mathrm{CH}_{4}$ is equivalent to releasing $16 \mathrm{~g} / \mathrm{d} \mathrm{H}_{2}$. It appears that $<2 \%$ of the spared $\mathrm{H}_{2}$ was released as gas, indicating that $>98 \%$ was diverted toward dissolved $\mathrm{H}_{2}$ and alternate $\mathrm{H}_{2}$ sinks in the rumen (e.g., such as formate, propionate, valerate, caproate, heptanoate, unsaturated fatty acids, nitrate and sulfate reduction, and microbial protein synthesis; Guyader et al., 2017). This shift in $\mathrm{H}_{2}$ flow within the rumen toward nutritionally beneficial sinks may partially account for the observed improvement in G:F.

\section{Implications for Sustainable Beef Production}

Approximately $80 \%$ of Nationally Determined Contributions to meet the commitments of the Paris Agreement specifically mention agriculture [(Food and Agriculture Organization of the United Nations (FAO), 2019a)], highlighting its important role in mitigating GHG emissions. Additionally, 54 countries have set goals of decreasing emissions from livestock (Richards et al., 2015). Consequently, beef production, which has the greatest GHG emissions per gram of protein produced (Poore and Nemecek, 2018), is under increasing pressure to decrease emissions. The GHG intensity ( $\mathrm{kg} \mathrm{CO} 2$ equivalent $/ \mathrm{kg}$ carcass) of beef production continues to decrease over time in many countries (e.g., 14.5\% decrease between 1981 and 2011 in Canada; Legesse et al., 2016), due to improvements in management, health, nutrition, and genetics of animals, as well as manure management, grazing management, crop production and decreased land conversion (Mayberry et al., 2019). However, a decrease in GHG intensity due to improved efficiency of production will not be sufficient to meet targets for absolute GHG reductions if animal production continues to expand to meet the demand for food security. As enteric $\mathrm{CH}_{4}$ represents more than $50 \%$ of farm-based GHG emissions of beef production (Beauchemin and McGeough, 2013), reducing enteric $\mathrm{CH}_{4}$ emissions has been identified as a key means of reducing emissions from the red meat sector (Mayberry et al., 2019). Thus, providing beef producers with effective mitigation options is critical. The present study conducted under commercial feedlot conditions confirms previous small scale research studies that show 3-NOP has tremendous potential for $\mathrm{CH}_{4}$ mitigation for beef production (Vyas et al., 2016a, 2018).
Achieving carbon neutral beef production will undoubtedly increase the cost of production as well as the retail price of meat (Mayberry et al., 2019). Some of the additional costs to farmers of using $\mathrm{CH}_{4}$ inhibiting feed additives may be at least partially offset by revenues from participating in voluntary carbon offset markets. For example, beef feedlots in Alberta, Canada, can participate in the Alberta Emission Offset System (www.alberta.ca/alberta-emission-offset-system.aspx) by quantifying reductions in $\mathrm{CH}_{4}$ using scientifically valid methodologies. Furthermore, improvements in animal performance would lead to greater revenues per animal sold. The observed tendency in feed conversion efficiency improvement $(2.5 \%)$ in the present study would be economically significant to the cattle industry, as feed costs represent the largest source of total input costs $(>60 \%)$. Feed conversion efficiency has a substantial impact on revenue per animal sold (Retallick et al., 2013). For example, using current feed costs, a $1 \%$ improvement in feed conversion efficiency is estimated to save the Canadian feedlot sector $\$ 11.1$ million annually (Buchanan-Smith and Wood, 2019). The Canadian beef industry is the 11th largest beef-producing country and the 5th largest exporter of beef globally [(Food and Agriculture Organization of the United Nations (FAO), 2019b)] with over 2.5 million cattle finished annually (Statistics Canada, 2019). In the U.S., where there are over 11 million beef cattle on feed at any one time (Cowley et al., 2019), the impact of feeding 3-NOP on reducing $\mathrm{CH}_{4}$ emissions and improving feed conversion efficiency could be substantial. Furthermore, improvements in feed conversion efficiency decrease the demand for feed inputs resulting in fewer GHG emissions from feed production, less land required for feed production, and decreased manure output (Beauchemin et al., 2011). Thus, the observed $2.5 \%$ improvement in G:F and $21.7 \%$ decrease in $\mathrm{CH}_{4}$ yield in the present study could have both significant environmental and economic implications for beef production systems in North America and elsewhere, if 3-NOP is approved by licensing authorities and made commercially available. However, further studies are needed to validate the efficacy of 3-NOP for $\mathrm{CH}_{4}$ mitigation and determine its effects on animal performance when used in commercial beef production systems with varying animal types, diets (including high-grain finishing diets), and management conditions.

\section{CONCLUSIONS}

This research is the first to show the effects of feeding 3-NOP on feed consumption, animal performance, animal health and enteric $\mathrm{CH}_{4}$ production of beef cattle fed a backgrounding diet in a commercial feedlot. Feeding 3-NOP tended to reduce DMI but improved G:F by $2.5 \%$. No negative impacts on animal health (mortality and morbidity) were observed. Feeding 3-NOP resulted in a sustained reduction in enteric $\mathrm{CH}_{4}$ yield of $22 \%$, on average (ranging from 20 to $26 \%$ depending upon dose). Assuming it becomes commercially available, 3-NOP has great potential to reduce GHG emissions from the beef industry, particularly the feedlot sector where use of feed additives and nutritional supplements is commonplace. 


\section{DATA AVAILABILITY STATEMENT}

The original contributions presented in the study are included in the article/supplementary material, further inquiries can be directed to the corresponding author.

\section{ETHICS STATEMENT}

The animal study was reviewed and approved by Animal Care committee at the Lethbridge Research and Development Centre, Agriculture and Agri-Food Canada according to Canadian Council on Animal Care (2009) and with approval of the Veterinary Drug Directorate of Health Canada (DSTS No. 207171).

\section{AUTHOR CONTRIBUTIONS}

All authors have made a substantial direct and intellectual contribution to the work ranging from inception of the project idea, searching for funding, project implementation and management, data collection and analysis to writing, and editing

\section{REFERENCES}

Alemu, A. W., Romero-Pérez, A., Araujo, R. C., and Beauchemin, K. A. (2019). Effect of encapsulated nitrate and microencapsulated blend of essential oils on growth performance and methane emissions from beef steers fed backgrounding diets. Animals 9:21. doi: 10.3390/ani9010021

Alemu, A. W., Shreck, A. L., Booker, C. W., McGinn, S. M., Pekrul, L. K. D., Kindermann, M., et al. (2020). Use of 3-nitrooxypropanol in a commercial feedlot to decrease enteric methane emissions from cattle fed a corn-based finishing diet. J. Anim. Sci. 99:skaa394. doi: 10.1093/jas/skaa394

AOAC (2016). Official Methods of Analysis of AOAC International. 20th ed. Gaithersburg, MD: AOAC International.

Arthur, P. F., Barchia, I. M., Weber, C., Bird-Gardiner, T., Donoghue, K. A. R., Herd, M., et al. (2017). Optimizing test procedures for estimating daily methane and carbon dioxide emissions in cattle using short-term breath measures. J. Anim. Sci. 95, 645-656. doi: 10.2527/jas2016.0700

Beauchemin, K. A., Janzen, H. H., Little, S. M., McAllister, T. A., and McGinn, S. M. (2011). Mitigation of greenhouse gas emissions from beef production in western Canada - evaluation using farm-based life cycle assessment. Anim. Feed Sci. Technol. 166-167, 663-677. doi: 10.1016/j.anifeedsci.2011.04.047

Beauchemin, K. A., and McGeough,. E. J. (2013). "Life-cycle assessment in ruminant production," in Sustainable Animal Agriculture, ed E. Kebreab (Oxfordshire: CABI), 212-317.

Beauchemin, K. A., Ungerfeld, E. M., Eckard, R. J., and Wang, M. (2020). Review: fifty years of research on rumen methanogenesis: lessons learned and future challenges for mitigation. Animal 14, S2-S16. doi: 10.1017/S1751731119003100

Beck, M. R., Thompson, L. R., White, J. E., Williams, G. D., Place, S. E., Moffet, C. A., et al. (2018). Whole cottonseed supplementation improves performance and reduces methane emissions intensity of grazing beef steers. Prof. Anim. Sci. 34, 339-345. doi: 10.15232/pas.2018-01722

Bello, N. M., and Renter, D. G. (2017). Invited review: reproducible research from noisy data: revisiting key statistical principles for the animal sciences. J. Dairy Sci. 101, 5679-5701. doi: 10.3168/jds.2017-13978

Buchanan-Smith, J., and Wood, K. (2019). Optimizing Feedlot Feed Efficiency. Beef Cattle Research Council. Available online at: www.beefresearch.ca/research-topic.cfm/optimizing-feedlot-feed-efficiency- 8 (accessed April 10, 2020).

Canadian Council on Animal Care (2009). CCAC Guidelines on: The Care and Use of Farm Animals in Research, Teaching and Testing. Ottawa, ON: Canadian Council on Animal Care. Available online at: www.ccac.ca/en_/standards/guidelines (accessed March 10, 2017). of the manuscript. All authors have approved the manuscript for publication.

\section{ACKNOWLEDGMENTS}

This research project was managed by Viresco Solutions (Edmonton, Alberta) and funded by Emissions Reduction Alberta (ERA, Edmonton, AB, Project F0160164) and DSM Nutritional Products (Basel, Switzerland). In-kind contributions of Agriculture and Agri-Food Canada (AAFC) and the expertise of Feedlot Health Management Services (FHMS, Okotoks, Alberta) staff for implementing the study at the feedlot are recognized. The authors also thank the management and staff of the commercial feedlot facility for their cooperation in conducting the study, Bev Farr (AAFC), Nicholaus Johnson (AAFC), and Jean-François Coulombe (AAFC) for assistance in equipment setup and maintenance, Bev Farr and Christian Sapsford (AAFC) for laboratory analysis, and Dr. Katrien Schäfer (DSM Nutritional Products) for analysis of 3-NOP in feed samples. We also thank Drs. Nicola Walker and Alex Karagiannis (DSM Nutritional Products) for their helpful suggestions on an earlier draft of the manuscript.

Cowley, F., Jennings, J., Cole, A., and Beauchemin, K. (2019). Review: recent advances to improve nitrogen efficiency grain-finishing in North American and Australian feedlots. Anim. Prod. Sci. 59, 2082-2092. doi: 10.1071/AN19259

Custodio, S. A. S., Tomaz, M. P. P., da Silva, D. A. L., Goulart, R. O., Dias, K. M., and de Carvalho, E. R. (2017). Feeding behavior of beef cattle fed different forages and housed in individual or collective pens. J. Anim. Behav. Biometeorol. 5, 20-28. doi: 10.14269/2318-1265/jabb.v5n1p20-28

Dijkstra, J., Bannink, A., France, J., Kebreab, E., and van Gastelen, S. (2018). Short communication: Antimethanogenic effects of 3-nitrooxypropanol depend on supplementation dose, dietary fiber content, and cattle type. J. Dairy Sci. 101, 9041-9047. doi: 10.3168/jds.2018-14456

Duin, E. C., Wagner, T., Shima, S., Prakash, D., Cronin, B., Yáñez-Ruiz, D. R., et al. (2016). Mode of action uncovered for the specific reduction of methane emissions from ruminants by the small molecule 3-nitrooxypropanol. Proc. Nat. Acad. Sci. U.S.A. 113, 6172-6177. doi: 10.1073/pnas.1600 298113

Food and Agriculture Organization of the United Nations (FAO) (2019a). Agriculture and Climate Change - Challenges and Opportunities at the Global and Local Level - Collaboration on Climate-Smart Agriculture. Rome. Available online at: www.fao.org/3/CA3204EN/ca3204en.pdf (accessed March 19, 2020).

Food and Agriculture Organization of the United Nations (FAO) (2019b). Meat Market Review: 2019 Outlook. FAO. Available online at: www.fao.org/economic/est/est-commodities/meat/meat-and-meat-productsupdate/en/ (accessed March 19, 2020).

Gerber, P. J., Steinfeld, H., Henderson, B., Mottet, A., Opio, C., Dijkman, J., et al. (2013). Tackling Climate Change Through Livestock - A Global Assessment of Emissions and Mitigation Opportunities. Rome: Food and Agriculture Organization of the United Nations (FAO). Available online at: www.fao.org/3/a-i3437e.pdf (accessed April 13, 2020).

Government of Canada (2019). Technical Paper: Federal Carbon Pricing Backstop. Available online at: www.canada.ca/en/services/environment/weather/climatechange/technical-pap er-federal-carbon-pricing-backstop.html (accessed September 17, 2019).

Gunter, S. A., and Bradford, J. A. (2015). Influence of sampling time on carbon dioxide and methane emissions by grazing cattle. Proc. West. Sec. Am. Soc. Anim. Sci. 66, 201-203.

Guyader, J., Ungerfeld, E. M., and Beauchemin, K. A. (2017). Redirection of metabolic hydrogen by inhibiting methanogenesis in the rumen simulation technique (RUSITEC). Front. Microbiol. 8:393. doi: 10.3389/fmicb.2017.00393

Hristov, A. N., Oh, J., Giallongo, F., Frederick, T. W., Harper, M. T., Weeks, H. L., et al. (2015). An inhibitor persistently decreased enteric methane emission 
from dairy cows with no negative effect on milk production. Proc. Natl. Acad. Sci. U.S.A. 112, 10663-10668. doi: 10.1073/pnas.1504124112

Hristov, A. N., Oh, J., Lee, C., Meinen, R., Montes, F., Ott, T., et al. (2013). "Mitigation of greenhouse gas emissions in livestock production - a review of technical options for non- $\mathrm{CO}_{2}$ emissions," in FAO Animal Production and Health Paper No. 177, eds P. J. Gerber, B. Henderson, and H. P. S. Makkar (Rome: FAO), 226

Intergovernmental Panel on Climate Change (IPCC) (2013). Climate Change 2013: The Physical Science Basis. Contribution of Working Group I to the Fifth Assessment Report of the Intergovernmental Panel on Climate Change. Cambridge; New York, NY: Cambridge University Press.

Intergovernmental Panel on Climate Change (IPCC) (2018). "Global warming of $1.5^{\circ} \mathrm{C}$. An IPCC special report on the impacts of global warming of $1.5^{\circ} \mathrm{C}$ above pre-industrial levels and related global greenhouse gas emission pathways, in the context of strengthening the global response to the threat of climate change, sustainable development, and efforts to eradicate poverty," in Intergovernmental Panel on Climate Change, eds V. Masson-Delmotte, P. Zhai, H.-O. Pörtner, D. Roberts, J. Skea, P. R. Shukla, et al. Available online at: www.ipcc.ch/sr15 (accessed July 17, 2020).

Kim, S. H., Lee, C., Pechtl, H. A., Hettick, J. M., Campler, M. R., Pairis-Garcia, M. D., et al. (2019). Effects of 3-nitrooxypropanol on enteric methane production, rumen fermentation, and feeding behavior in beef cattle fed a high-forage or high-grain diet. J. Anim. Sci. 97, 2687-2699. doi: 10.1093/jas/skz140

Lee, C., Kim, S.-H., Beauchemin, K., Celi, P., and Duval, S. (2019). Short-term eating preference of beef cattle fed high forage or high grain diets supplemented with 3-nitrooxypropanol. Animal 10:64. doi: 10.3390/ani10010064

Legesse, G., Beauchemin, K. A., Ominski, K. H., McGeough, E. J., Kroebel, R., MacDonald, D., et al. (2016). Greenhouse gas emissions of Canadian beef production in 1981 as compared with 2011. Anim. Prod. Sci. 56, 153-168. doi: 10.1071/AN15386

Manafiazar, G., Zimmerman, S., and Basarab, J. A. (2016). Repeatability and variability of short-term spot measurement of methane and carbon dioxide emissions from beef cattle using GreenFeed emissions monitoring system. Can. J. Anim. Sci. 97, 118-126. doi: 10.1139/cjas-2015-0190

Martinez-Fernandez, G., Duval, S., Kindermann, M., Schirra, H. J., Denman, S. E., and McSweeney, C. S. (2018). 3-NOP vs. halogenated compound: methane production, ruminal fermentation and microbial community response in forage fed cattle. Front. Microbiol. 9:1582. doi: 10.3389/fmicb.2018.01582

Mayberry, D., Bartlett, H., Moss, J., Davison, T., and Herrero, M. (2019). Pathways to carbon-neutrality for the Australian red meat sector. Agric. Syst. 175, 13-21. doi: 10.1016/j.agsy.2019.05.009

McGinn, S. M., Flesch, T. K., Beauchemin, K. A., and Kindermann, M. (2019). Micrometeorological methods for measuring methane emission reduction at beef cattle feedlots: Evaluation of 3-nitrooxypropanol feed additive. J. Environ. Qual. 48, 1454-1461. doi: 10.2134/jeq2018.11.0412

Muller, R. A., and Muller, E. A. (2017). Fugitive methane and the role of atmospheric half-life. Geoinfor. Geostat. Overview 5, 2-7. doi: 10.4172/2327-4581.1000162

Poore, J., and Nemecek, T. (2018). Reducing food's environmental impacts through producers and consumers. Science 360, 987-992. doi: 10.1126/science.aaq0216

Retallick, K. M., Faulkner, D. B., Rodriguez-Zas, S. L., Nkrumah, J. D., and Shike, D. W. (2013). Relationship among performance, carcass, and feed efficiency characteristics, and their ability to predict economic value in the feedlot. $J$. Anim. Sci. 91, 5954-5961. doi: 10.2527/jas.2013-6156

Richards, M., Bruun, T. B., Campbell, B., Gregersen, L. E., Huyer, S., Kuntze, et al. (2015). How Countries Plan to Address Agricultural Adaptation and Mitigation: An Analysis of Intended Nationally Determined Contributions. CCAFS Info Note. Copenhagen: CGIAR Research Program on Climate Change, Agriculture and Food Security (CCAFS). Availale online at: https://hdl.handle.net/10568/ 69115

Romero-Perez, A., Okine, E. K., McGinn, S. M., Guan, L. L., Oba, M., Duval, S. M., et al. (2014). The potential of 3-nitrooxypropanol to lower enteric methane emissions from beef cattle. J. Anim. Sci. 92, 4682-4693. doi: $10.2527 /$ jas.2014-7573

Romero-Perez, A., Okine, E. K., McGinn, S. M., Guan, L. L., Oba, M., Duval, S. M., et al. (2015). Sustained reduction in methane production from long-term addition of 3-nitrooxypropanol to a beef cattle diet. J. Anim. Sci. 93, 1780-1791. doi: $10.2527 /$ jas.2014-8726
Schutz, J. S., Wagner, J. J., Neuhold, K. L., Archibeque, S. L., and Engle, T. E. (2011). Effect of feed bunk management on feedlot steer intake. Prof. Anim. Sci. 27, 395-401. doi: 10.15232/S1080-7446(15)30511-8

Schwartzkopf-Genswein, K. S., Beauchemin, K. A., Gibb, D. J., Crews, D. H. Jr., Hickman, D. D., Streeter, M., et al. (2003). Effect of bunk management on feeding behavior, ruminal acidosis and performance of feedlot cattle: a review. J. Anim. Sci. 81(Suppl. 2), 149-158. doi: 10.2527/2003.8114_suppl_2E149x

Smith M. L. (2017). Assessing the potential of a novel feed additive and an unsaturated fat alone and in combination to lower methane emission from cattle and reduce their contribution to climate change (Ph.D. Thesis), University of Delaware, Newark, DE, United States. Available online at: https://udspace.udel. edu/handle/19716/23161 (accessed September 2020).

Statistics Canada (2019). Table 32-10-0130-01. Number of Cattle, by Class and Farm Type $(x 1,000)$. Available online at: www150.statcan.gc.ca/t1/tbl1/en/tv.action? pid $\$=\$ 3210013001$ (assessed October 5, 2020).

Step, D. L., Krehbiel, C. R., DePra, H. A., Cranston, J. J., Fulton, R. W., Kirkpatrick, J. G., et al. (2008). Effects of commingling beef calves from different sources and weaning protocols during a forty-two-day receiving period on performance and bovine respiratory disease. J. Anim. Sci. 86, 3146-3158. doi: $10.2527 /$ jas.2008-0883

Velazco, J. I., Mayer, D. G., Zimmerman, S., and Hegarty, R. S. (2016). Use of shortterm breath measures to estimate daily methane production by cattle. Animal 10, 25-33. doi: $10.1017 /$ S1751731115001603

Vyas, D., Alemu, A. W., McGinn, S. M., Duval, S. M., Kindermann, M., and Beauchemin, K. A. (2018). The combined effects of supplementing monensin and 3-itrooxypropanol on methane emissions, growth rate, and feed conversion efficiency in beef cattle fed high-forage and high-grain diet. J. Anim. Sci. 96, 2923-2938. doi: 10.1093/jas/sky174

Vyas, D., McGinn, S. M., Duval, S. M., Kindermann, M., and Beauchemin, K. A. (2016a). Effects of sustained reduction of enteric methane emissions with dietary supplementation of 3-nitrooxypropanol on growth performance of growing and finishing beef cattle. J. Anim. Sci. 94, 2024-2034. doi: $10.2527 /$ jas2015-0268

Vyas, D., McGinn, S. M., Duval, S. M., Kindermann, M., and Beauchemin, K. A. (2016b). Optimal dose of 3-nitrooxypropanol for decreasing enteric methane emissions from beef cattle fed high-forage and high-grain diets. Anim. Prod. Sci. 58, 1049-1055. doi: 10.1071/AN15705

Conflict of Interest: LP, AS, and CB were employed by Feedlot Health Management Services. MK was employed by DSM Nutritional Products, a funder of the study.

The remaining authors declare that the research was conducted in the absence of any commercial or financial relationships that could be construed as a potential conflict of interest.

The authors declare that this study received funding from Emissions Reduction Alberta (ERA, Edmonton, AB, Project F0160164), DSM Nutritional Products (Basel, Switzerland), and the Alberta Cattle Feeders Association (ACFA, Calgary, $\mathrm{AB}$ ), with in-kind contributions of Agriculture and Agri-Food Canada (AAFC). Viresco Solutions (Edmonton, Alberta) managed the project in a consultancy role, while Feedlot Health Management Services (FHMS, Okotoks, Alberta) implemented the study at the feedlot. Authors employed by DSM, AAFC and FHMS contributed to all aspects of the study: design, data collection and analysis, interpretation of results, and preparation of the manuscript. ERA, Viresco Solutions and ACFA were not involved in conducting the study or writing this article.

Copyright (๑) 2021 Liana K. D. Pekrul, Adam L. Shreck, Calvin W. Booker, Maik Kindermann and Her Majesty the Queen in Right of Canada, as represented by the Minister of Agriculture and Agri-Food Canada for the contribution of Aklilu W. Alemu, Sean M. McGinn, and Karen A. Beauchemin. This is an open-access article distributed under the terms of the Creative Commons Attribution License (CC BY). The use, distribution or reproduction in other forums is permitted, provided the original authors and the copyright owners are credited and that the original publication in this journal is cited, in accordance with accepted academic practice. No use, distribution or reproduction is permitted which does not comply with these terms. 